\title{
"Violência? Do quê?": reflexões sobre a violência obstétrica a partir de uma ação extensionista
}

\author{
Paula Land Curi \\ paulalandcuri@id.uff \\ Natália Lucena Guimarâes \\ nlg.natalia.lucena@gmail.com \\ Universidade Federal Fluminense | Brasil
}

\section{Resumo}

Este trabalho objetiva discutir a violência obstétrica, a partir de uma ação extensionista realizada em uma Unidade Básica de Saúde, no município de Niterói, RJ, em comemoração ao Dia Internacional da Mulher. Com usuárias do sistema de saúde, em idades diversas, a Roda de Conversa proposta teria a intenção de orientálas sobre a rede de assistência e proteção para os casos de exposição à violência sexual e/ou doméstica. Contudo, o que se apresentou foi a tão naturalizada violência obstétrica. Embora não conseguissem nomear as violências vividas, as mulheres deixavam claro que, em nome da assistência ao parto, elas eram desassistidas e expostas a muito sofrimento e dor.

\section{Palavras-chave}

Ação extensionista; Violência obstétrica; Assistência ao parto. 


\section{Introdução}

Em pouco mais de um século, o parto deixou de ser uma experiência da esfera familiar e íntima, compartilhada entre mulheres, para se tornar uma prática dominada pela medicina, institucionalizada nos hospitais e regulada por políticas públicas. (MAIA, 2010, p. 13).

Sabemos que o parto é um fenômeno biopsicossocial e que, atualmente, está também intimamente ligado a aspectos econômicos, visto que o modelo de assistência é regido por uma lógica de mercado de produção, intervencionista de organização, que visa otimizar o tempo do profissional e da maternidade (WAGNER, 2001; AGUIAR, 2010). Consequentemente, podemos dizer que o parto tece, em seu entorno, uma enorme rede de relações de forças.

Há muito tempo, ele já deixou de ser visto como um evento natural, meramente fisiológico e familiar para tornar-se médico, cirúrgico e hospitalar, sendo a mulher mera coadjuvante deste novo cenário, masculino e médico. "Com a mulher deitada na cama, de pernas para cima e abertas, fica claro que o sujeito do parto é o médico, e não a mulher" (MAIA, 2010, p. 36), agora tornada objeto passivo do discurso da obstetrícia.

Ao longo dos anos, o lar fora substituído pelos hospitais maternidades, lugares do parir com segurança, tendo em vista os "avanços" possibilitados, inclusive, pela descoberta da assepsia e da analgesia. A partir de então, a mulher passa a contar com a possibilidade de parir sem dor e com "menos chance" de morrer vítima da devastadora febre puerperal - infecção generalizada causada por estreptococos, recorrente até o século XIX.

No entanto, mesmo com a progressiva patologização e medicalização do parto, com o controle exercido pelo saber médico sobre o corpo da mulher (BARBOZA; MOTA, 2016), o ato de parir nunca deixou de ser acompanhado de dor. Afinal, o discurso médico da obstetrícia, longe de querer promover bem-estar, esteve sempre a serviço da disciplina, da fabricação dos chamados corpos dóceis.

A dor, além de ser um evento biológico, também é uma construção sociocultural, e em relação ao processo do parto a vivência da dor é influenciada pela forma como a sociedade interpreta o ato de parir, pela história de vida da parturiente, pelas experiências prévias de parto desta mulher e de seus familiares, pelo preparo desta mulher e pelo acolhimento no momento do parto. (BARBOZA; MOTA, 2016, p. 123).

Na metade do século XX, mais exatamente em 1950, a feminista Adrienne Rich problematiza o que se apresentava como experiência compartilhada na vida de várias 
mulheres, deixando evidente que a mulher, no momento de parir, não era nem protagonista, nem autônoma.

Parimos em hospitais (...) negligentemente drogadas e amarradas contra a nossa vontade, (...) nossos filhos retirados de nós até que outros especialistas nos digam quando podemos abraçar nossos recém-nascidos. (RICH, 1979, p. 269 apud DINIZ, 2016, p. 378).

Seria inepto dizer que não existam outros relatos que façam menção ao sofrimento da mulher, quando na assistência ao parto. Pelo contrário, estamos cônscios que são muitos os registros e relatos que apontam para as tormentas das mulheres no parir e que eles atravessam muitos e diferentes momentos históricos.

A Conferência de Beijing (1995) anuncia, no campo da saúde da mulher, a entrada de um novo século, pois, compreende que o fortalecimento das mulheres se dá através de "investimentos na melhoria de suas condições de saúde e de educação, da eliminação da violência que sobre elas se abate” (ONU, 1996, p, 12). E, o Brasil, país signatário, reafirma seu compromisso com a agenda, comprometendo-se a:

Adotar todas as medidas necessárias para acabar com as intervenções médicas prejudiciais à saúde, intervenções desnecessárias do ponto de vista médico e coercitivas, e com os tratamentos inadequados e administração excessiva de medicamentos à mulher. (ONU, 1996, p. 83).

Podemos dizer que, como efeito dos tratados internacionais e das políticas internas voltadas às mulheres, das críticas ao modelo do parto excessivamente medicalizado e atentas aos índices absurdos de cesáreas desnecessárias, a partir do ano 2000, o tema da violência no parto passou a ser amplamente discutido no Brasil, especialmente, com a elaboração da Política Nacional de Humanização do Parto. Estava clara a necessidade de se transmutar a realidade da assistência brasileira, qualificando o cuidar de mulheres durante a gestação, parto e puerpério.

A saúde no Brasil, seu modelo de assistência, constituiu-se centrada em práticas médico-hospitalares e curativistas. E, em relação ao parto, isso não se deu de forma distinta. Hospitalar, "com apoio tecnológico e fármaco-químico, nos moldes de uma montagem taylorista, tem se tornado o modelo predominante, quando não hegemônico, de assistência ao parto". (MAIA, 2010, p. 36).

Neste modelo de assistência, tecnocrático, resta à mulher duas alternativas, como aponta Maia (2010): "um parto vaginal traumático, pelo excesso de intervenções, ou uma cesárea" (p. 37), ou ainda, a "substituição do risco potencial de resultados adversos 
pelo risco certo de tratamentos e intervenções duvidosas" (DINIZ, 2001 apud MAIA, 2010, p. 37).

A partir das críticas ao modelo do parto medicalizado, surgiu, há algumas décadas, o movimento em prol do parto humanizado, propondo "novos" desafios: "promover partos e nascimentos saudáveis, que garantam a privacidade, a autonomia e o protagonismo da mulher". (MAIA, 2010, p. 42).

Atento às questões que atravessavam a saúde das mulheres e o trágico cenário brasileiro, o Ministério da Saúde, através de suas normas técnicas, na virada do século XXI, criou diretrizes sobre a assistência ao parto. Implantou o Programa de Humanização ao Pré-Natal e Nascimento (2000), assim como Política Nacional de Atenção Obstétrica e Neonatal (2005), na tentativa de consolidar "um paradigma de humanização da assistência à parturição, que possa se sobrepor ao modelo hoje prevalecente, calcado em uma excessiva medicalização, e minimizar os impactos negativos da hospitalização do parto". (MAIA, 2010, p. 9).

O Estado brasileiro incorporou este novo paradigma como "estratégia privilegiada para tentar reduzir tanto os índices de morte materna quanto para garantir a saúde materna" (MAIA, 2010, p. 48), visto que se percebeu:

As intervenções do modelo tecnocrático de assistências ao parto geram um efeito em cascata, ou seja, médicos submetem as mulheres a intervenções que podem levara complicações, gerando intervenções subsequentes, e a mais complicações, que terminam em sua intervenção final, em geral numa cesárea, que não teria ocorrido se a cascata na tivesse iniciado. (MOLD; STEIN, 1986; DINIZ, 2001 apud MAIA, 2010, 37).

Apesar de, em certo sentido, podermos dizer que temos hoje um cenário dividido entre dois modelos: tecnocrático, advindo da lógica médica; e humanístico, centrado no protagonismo e autonomia da mulher, não nos podemos esquivar de corroborar Maia (2010), quando ela sinaliza que o processo de institucionalização do parto, no Brasil, foi bem sucedido, uma vez que segue sendo predominantemente medicalizado e hospitalar. Ele não foi capaz de garantir a saúde materna. Intervenções excessivas, padronizadas, danosas, ineficazes e, absurdamente, violentas têm sido constantemente vivenciadas.

A despeito de todo este cenário, que traz consigo a marca das violências às quais a mulher sofre, foi somente a partir da segunda década do século XXI, que pudemos mais efetivamente reconhecer e explicitar as circunstâncias violentas e constrangedoras que 
se apresentam em torno do parir e criarmos para ela uma designação específica: violência obstétrica.

Sena e Tesser (2015) ratificam que, somente a partir de 2010, no Brasil, "passouse a utilizar a expressão violência obstétrica" (p. 3) para expressar formas de violências e danos, que advém do cuidado obstétrico. Salientam também que o vocábulo ainda está mal definido, sujeito a polêmicas diversas, inviabilizado "pela legitimização do conhecimento médico hegemônico" (p. 4), assim como desconhecido pela população. Contudo, para Andrade e Aggio (2014, p. 6), "a violência obstétrica é ainda pouco reconhecida enquanto um ato violento, pois no mesmo momento que ela ocorre, as mulheres estão vivenciando marcantes emoções, que as fazem se calar".

Seguindo esta linha de discussão, este trabalho objetiva tecer algumas considerações sobre este tipo de violência, que, ao mesmo tempo, comporta algo de antigo e de novo, de estranho e de familiar. Para este fim, vamos nos basear em uma ação extensionista, realizada em uma Unidade Básica de Saúde (UBS), no município de Niterói, em comemoração ao Dia Internacional da Mulher.

Reafirmamos, com Sena e Tesser (2015), que para se conseguir uma efetiva mudança neste cenário violento, que se constituiu em torno da saúde sexual e reprodutiva da mulher, torna-se fundamental colocar em pauta as relações de poder e de dominação sobre a mulher e o seu corpo. E para isso, necessitamos da participação das próprias mulheres.

\section{Na Unidade Básica de Saúde: “Violência? De quê?”}

Em 2014, a paranaense teve seu primeiro filho. Só depois descobriu que os maus tratos que sofreu não eram admissíveis. (LAZZERI, 2015, documento eletrônico).

Dia Internacional da Mulher, diversos dispositivos de saúde se organizam para comemorá-lo, buscando propor ações capazes de convocar as mulheres, não só a se aproximarem de suas unidades de referência, mas também participarem de atividades em seus territórios, discutindo temas que lhes possam ser pertinentes e de interesse.

Neste contexto de homenagem, fomos convidados a participar, enquanto integrantes de um projeto extensionista, de uma Roda de Conversa, em uma Unidade Básica de Saúde (UBS), no município de Niterói. 
Poderíamos dizer que o tema escolhido não era dos mais convidativos. Afinal, nós iríamos tratar de um tipo de violência bastante devastadora, que atravessa a vida das mulheres - o estupro, embora os objetivos desta ação fossem aparentemente simples: orientar sobre os dispositivos de acolhimento (unidades de referência) e proteção disponíveis na cidade, entregar panfletos informativos e criar um mural interativo com as mulheres.

As mulheres tinham clareza que violência sexual atravessava suas vidas. Sobre isso, não tinham qualquer dúvida. Mas, desconheciam o fato dos municípios brasileiros contarem com uma rede de proteção e assistência às mulheres em situação de violência.

Dos pequenos abusos vivenciados no dia a dia de mulher, numa sociedade sexista, às violências domésticas e intrafamiliares cotidianas, elas começaram a deslizar para contar outras histórias, vivenciadas por elas, amigas, irmãs, cunhadas, vizinhas e mesmo filhas durante suas gravidezes e partos.

No lugar da violência sexual, começa, então, a surgir nas falas das mulheres, um tom de desconfiança, que há muitas outras formas de violências em jogo em suas vidas. Violência sexual seria apenas uma delas e nem presente na vida de todas. E, assim, a Roda passa a girar em outra direção. Elas não queriam falar de estupros.

Seria simples manter o foco da conversa naquilo que havíamos preparado. Mas, consequentemente, perderíamos aquilo que é mais rico nesse tipo de ação: "estar entre sujeitos e saberes diversos, entre espaços e tempo diversos, entre práticas e problemáticas cotidianas". (CURI; BAPTISTA, 2016, p. 270). Afinal, para que a Extensão possa exercer sua potência transformadora, emancipatória e democrática, deve ser, além de desenvolvida no diálogo e respeito aos sujeitos em suas culturas locais, devem criar novas possibilidades, saídas emancipatórias, que possam se inscrever em seus corpos e vidas. (CURI; BAPTISTA, 2016).

Deixamos os nossos scripts de lado e, assim, histórias foram sendo narradas, compartilhadas. Uma rede foi sendo tecida entre elas, visto que todas evidenciavam que haviam sido subjugadas, no momento do parto, desrespeitadas quanto à sua autonomia e, especialmente, às suas histórias de vidas.

Nenhum dos relatos parecia ser novidade para as participantes da roda. Todavia, eram reconhecidos e compartilhados por elas, associados a um estranho sentimento de culpa e admitidos como vivências 'normais'. 
$\mathrm{Na}$ contramão dos instituídos, aquelas mulheres construíram suas próprias demandas e criaram para elas mesmas um momento singular. Conseguiram ali, algumas pela primeira vez, relatar a dor, a tristeza, os maus-tratos e a solidão, sem dar, aquilo que diziam ter vivido, necessariamente, a significação de violência.

Simplesmente, achavam que o que vivenciaram era 'normal', o único modo possível de parir, enquanto mulheres pobres e usuárias do Sistema Único de Saúde (SUS). Todos os desconfortos e estranhamentos relatados eram vistos como necessários para poderem parir com segurança, nos hospitais.

Mergulhadas nos aspectos imaginários que atravessam a maternidade - "algo divino, a expressão máxima de felicidade e plenitude da vida de uma mulher" - muitas delas jamais puderam falar sobre o que viveram de forma tão pessoal, embora ali nada lhes fosse apresentado como inédito. Todas compartilhavam as mazelas que lhes são impostas, cotidianamente, em nome de uma dita assistência ao parto.

Contudo, dirigiam-se a nós, 'escutadores' dessas narrativas de sofrimento e dor, representantes da academia, como se buscassem, através de nossos olhares, ratificar o caráter violento de suas vivências.

Aos poucos, elas puderam perceber que foram imersas em violências às quais sequer podiam nomear. Simplesmente, desconheciam-nas, ou melhor, estavam tão naturalizadas que eram tidas como "normais". Desconfortos e estranhamentos foram surgindo quando foram se dando conta que foram expostas a situações de violência por todos aqueles que lhes deveriam acolher e assistir.

0 compartilhar das existências, somado à circulação dos afetos, permitiu que elas não só colocassem o velho ditado popular em xeque - "ser mãe é padecer no paraíso" (?) - mas também possibilitou perceberem que a violência obstétrica se impunha, mesmo que esta adjetivação tenha sido trazida por nós.

\section{Do protagonismo feminino ao protagonismo médico}

Até o século XVI o cuidado com as doenças femininas pouco interessava aos médicos. 0 parto era um ritual de mulheres e quem assistia a mulher neste e em outros momentos era a parteira (RODHEN, 2001, p.59).

Se houve um tempo em que o ato de partejar era coisa exclusivamente de mulheres e os seus conhecimentos eram adquiridos em suas práticas cotidianas, nos domicílios das outras mulheres grávidas/parturientes, com o passar do tempo, este 
passou a ser questionado, especialmente pela Igreja, pelos possíveis abortos e infanticídios realizados, dando início a uma "caçada" às parteiras, em nome da problemática do controle demográfico. Consequentemente, podemos afirmar que, cerca de 300 anos, antes da institucionalização do parto nas maternidades, já se evidenciava um movimento na direção de medicalizar aquilo que era descrito como a 'arte de partejar'.

Entre os finais do século XVIII e a segunda metade do século XIX, o discurso científico, as reflexões dos médicos, suas descobertas e experimentos, sobre e no corpo feminino, contribuíram para a exploração de um campo anteriormente eminentemente feminino, "permitindo que homens da ciência entrassem em cena, desafiando o domínio e o poder das mulheres sobre seus corpos, a ponto de obstetras e ginecologistas serem considerados como especialistas em mulheres" (ALGRANTI, 2004, p. 8).

Assim, no século XIX, o partejar acabou por ser delegado ao médico, pois a obstetrícia havia surgido enquanto saber, ao mesmo tempo em que se efetivou "a hospitalização do parto e a criação de maternidade, instituições hospitalares exclusivas para esse fim". (VIEIRA, 2002, p. 47).

Gradativamente, as mulheres começaram a perceber que os médicos poderiam oferecer serviços que não estavam ao alcance das parteiras. Eles adquiriram formação técnica que lhes conferia status e lhes permitia administrar medicamentos e procedimentos não disponíveis no repertório das parteiras. (DIAS; DESLANDES, 2006, p. 354).

Ao término do século XIX, aquilo que era pertencente às mulheres, deslocou-se, definitivamente, das mãos das parteiras para as dos médicos - "homem culto, de princípio e o protetor da mulher" (MARTINS, 2004, p. 63) - de casa para as maternidades, em nome de um atendimento de qualidade, seguro, indolor e asséptico (MARTINS, 2004), apesar de certa resistência de mulheres a esse novo espaço, incialmente ainda visto como morredouro.

Todavia, em um tempo em que muitas mulheres morriam no parto, especialmente em consequência da febre puerperal, o hospital seria uma solução para o enfrentamento deste terrível problema, especialmente quando a anestesia e a assepsia já tinham surgido como seus grandes aliados.

No hospital estão protegidos, ela e o feto, pela tecnologia ali oferecida e reafirmada constantemente pela ideia de que o conhecimento é mais 
"Violência? Do que?": reflexões sobre a violência obstétrica a partir de uma ação extencionista

importante que os seus saberes ou valores culturais (DIAS; DESLANDES, 2006, p. 355).

Efetivamente, as descobertas da nova ciência médica afastaram a mulher do parto, tornando os obstetras os grandes protagonistas da nova cena médica, visto que sua conquista está intimamente relacionada com o uso de instrumentos devido ao avanço tecnológico da época.

Segundo Rohden (2006), por exemplo, o fórceps seria um desses instrumentos que fez ampliar o poderio médico, visto que, com ele, o cirurgião conseguiria ampliar as chances de salvar a criança. ${ }^{1}$ Mas, e a mulher? A ela caberia apenas obedecer às orientações daquele que dela saberia dizer.

Paulatinamente, os conhecimentos populares sobre o corpo grávido e parto, que outrora faziam parte de uma sabedoria popular, foram sendo perdidos, reforçando a ideias de que a parturição depende e faz parte do saber médico. (DIAS; DESLANDES, 2006, p. 355).

No Brasil, essa história ganhou contornos próprios, pois, durante todo o século XIX ainda se buscava parteiras ao invés de médicos, sendo esses últimos convocados, apenas "por ostentação ou em casos difíceis" (SANTOS FILHO, 1977, apud VIERA, 2002, p. 53). Isto porque a corte, quando veio para o Brasil, trouxe consigo parteiras estrangeiras que se tornaram profissionais regulamentadas.

As parteiras ocuparam um lugar fundamental, em nossa história, até bem pouco tempo. Mas, embora a obstetrícia tenha tardado em terras brasileiras, ela também se legitimou enquanto saber sobre o parto e nascimento, contribuindo para que o modelo tecnocrático de assistência se tornasse hegemônico, especialmente a partir dos anos 60 .

Contudo, Maia (2010) nos lembra que, de algumas décadas para cá, no Brasil, o parto passou a se apresentar como uma Política - Política do Parto. Porém, isso não surge e não avança sem grandes embates.

Um dos aspectos mais impressionantes da prática obstétrica brasileira é a pressa em provocar o nascimento das crianças, sem respeito à autonomia das mulheres no processo de parturição. 0 controle do tempo e a imposição da dinâmica do trabalho de parto e parto explicam o índice excessivo de intervenções, incluindo as cesarianas, fazendo com que a assistência ao parto no Brasil seja focada na decisão do médico e não na dinâmica do corpo da mulher. (LEAL et al., 2014).

\footnotetext{
${ }^{1}$ Rohden (2006) evidencia que Knibiehler e Fouquet (1983) haviam dito que o fato de os instrumentos
} terem permitido aos cirurgiões suplantar as parteiras implicou sua identificação com poder masculino. 


\section{Implementação da proposta}

As tensas e conflituosas relações entre ciência médica e corpo feminino conformam um campo em no qual historicamente vem se exercendo relações de poder, de opressão e controle político das mulheres. (BARBOSA, 2006, p. 323).

Na atualidade, no cenário da assistência ao parto, a discussão sobre a saúde integral tem levantado debates intensos e tem sido uma das principais responsáveis pelos questionamentos que enfrenta o atual modelo hegemônico do parto no Brasil. Quem tem a última palavra sobre o corpo da mulher? A proprietária deste corpo ou a Ordem Médica? Até onde vai a autonomia feminina?

Foucault (1978-1979) elucida o quanto a moralidade, a disciplina e as normas constroem modelos de agenciamentos da vida. Pode-se afirmar que o modelo de assistência ao parto, naturalizado, atualmente, na sociedade brasileira, está para a normalização da sexualidade e da reprodução. Inscreve-se no corpo feminino almejando a sua disciplinarização, para o sucesso do ato médico.

Diferentes instituições ideológicas ${ }^{2}$, tais como a família, a religião, a medicina, o sistema escolar, de justiça, de segurança, entre outras, constroem significados sobre a sexualidade e o gênero ditando modelos de normalidade e de comportamento, produzindo saberes de controle sobre corpos e desejos. (Foucault, 1988 apud FERREIRA; AGUINSKY, 2013, p. 224).

É mesmo no sentido de submissão que falamos de violência obstétrica. E isto está diretamente relacionada à forma como a mulher foi inserida na nossa sociedade - como mãe, despida de qualquer direito enquanto sujeito-mulher ou mesmo cidadã.

A naturalização do papel da mulher, enquanto mãe implica naquilo que é esperado delas, inclusive, no momento do parto - submissão ao poder médico e falta de capacidade e autonomia para participação ativa em seu processo de parir.

Faz-se necessário, assim, que seus corpos precisem estar submetidos à lógica do modelo vigente, mesmo que, para isso, seja necessário se lançar mão da violência, como meio de manter a disciplina e o controle do cenário em questão.

Pelo parir ter se tornado um ato médico, faz-se possível lançar mão de práticas intervencionistas as quais ignoram os aspectos perceptivos, emocionais e subjetivos do

\footnotetext{
2 Ferreira e Aguinsky (2013) indicam que, para Althusser (1970), "tais instituições ideológicas guardam correspondência ao que define como Aparelhos Ideológicos de Estado (AIE). São aquelas instituições especializadas responsáveis por reproduzirem a ideologia de acordo com as suas naturezas [...], que se diferenciam do aparelho repressivo do Estado por funcionarem prevalentemente pela ideologia e secundariamente pela violência (pois mobilizam violências de forma dissimulada ou simbólica". (p.231).
} 
próprio parir, em nome de um saber técnico, dominante e hegemônico. Isso coloca as mulheres em condição de maior vulnerabilidade à violência ${ }^{3}$.

Neste sentido, podemos dizer com Aguiar (2010), se a paciente não é reconhecida como um sujeito pelo profissional que a assiste, ela não é vista como alguém de direitos e que sofre. Ela estará, necessariamente, diante de um ato violento, corroborando, ainda mais, com Chauí (1985), que não hesita em assinalar que a violência pode se estabelecer "como conversão de uma diferença e de uma assimetria numa relação hierárquica de desigualdade com fins de dominação, de exploração e de opressão". (p. 35).

Se para a Organização Mundial da Saúde a violência obstétrica pode ser descrita como abusos, maus-tratos, negligência e o desrespeito durante o parto, que configuram violação dos direitos humanos fundamentais das mulheres (OMS, 2014), para Andrade e Aggio (2014, p. 5), este "tipo de violência é produzida por meio da hierarquia e dominação do saber médico sobre o corpo da mulher, ferindo diretamente a autonomia a respeito daquilo que somente pertence a elas, os seus corpos".

Ainda, segundo o autor, o atual modelo de assistência ao parto é regido por uma lógica do mercado de produção, que inviabiliza a individualização das singularidades e desejos de cada mulher. Afinal, "historicamente, o corpo feminino tem sido locus no qual incidem políticas de controle sobre a reprodução social, e o sistema de saúde tem sido poderoso aliado do Estado e dos poderes hegemônicos na consecução dessas políticas". (BARBOSA, 2006, p. 330).

Mas, o fato é que, dialeticamente, as mulheres, a "sua resistência à opressão e a exploração, particularmente no que diz respeito ao corpo e à saúde, vem gerando propostas e práticas de saúde que indicam radicais transformações nos modelos assistenciais vigentes". (BARBOSA, 2006, p. 323).

\section{Sobre as políticas de humanização do parto}

É a partir da identificação dos elementos que descaracterizaram, ao longo do tempo, no modelo biomédico, o processo de parturição até então centrado na mulher, que se tem dado a demanda por sua humanização. (DIAS; DESLANDES, 2006, p. 359).

\footnotetext{
3 Segundo Chauí (1985), violenta é a "ação que trata um ser humano não como sujeito, mas como uma coisa. Esta se caracteriza pela inércia, pela passividade e pelo silêncio, de modo que, quando a atividade e a fala de outrem são impedidas ou anuladas, há violência". (p. 35).
} 
As Políticas de Humanização do Parto e do Nascimento surgem na contramão da prática de assistência ao parto que foi sendo naturalizada, na prática médica obstétrica, nos últimos séculos.

Segundo Dias e Deslandes (2006), todos os benefícios oferecidos por esse modelo, quer em termos de segurança, quer em termos de tecnologias, passaram a ser questionados pelas mulheres, assim como por profissionais de saúde. Para os autores, "fatores de ordem social e cultural, e não apenas médicos, ganharam relevância na avaliação tanto da qualidade da assistência prestada como da satisfação das usuárias" (p. 360).

A humanização se apresenta como uma alternativa ao modelo tecnocrático, largamente difundido, visto que, de acordo com o Ministério da Saúde, o conceito de atenção humanizada é amplo e "envolve um conjunto de conhecimentos, práticas e atitudes que visam à promoção do parto e do nascimento saudáveis e a prevenção da morbimortalidade materna perinatal". (BRASIL, 2001, p. 9).

Apesar de todo um movimento em torno da dita humanização e a proposição de mudanças na atenção vigentes, o que se revela, é a necessidade de transformações nas práticas assistenciais, nas maneiras como estas podem ser operacionalizadas. (DIAS; DESLANDES, 2006). As transformações necessárias, segundo os autores, deveriam ser "de ordem relacional, com profissional de saúde trabalhando orientado por um novo marco ético" (DIAS; DESLANDES, 2006, p. 364).

Salientamos, porém, que necessitamos promover um novo marco ético, que possa incrementar, de fato, transformações na cultura hegemônica vigente. Dizemos isso porque não podemos esquecer a história recente do País, que se traduz em políticas públicas para as mulheres no parto, sem grandes efeitos, em termos práticos, na assistência.

Surgido em meio a um jogo de forças, entre pressões internacionais e nacionais, dentre as quais o movimento de mulheres, o PAISM - Programa Integral à Saúde da Mulher -, ainda no inicio da década de 80, com certeza, "foi um marco histórico ao propor um conjunto de diretrizes e princípios norteadores da assistência, incluindo demandas específicas do processo reprodutivo" (DIAS; DESLANDES, 2006, p. 362), visto que rompeu com as políticas reducionistas que o antecederam, fragmentadas em ações para geração de filhos sadios. 
"Violência? Do que?": reflexões sobre a violência obstétrica a partir de uma ação extencionista

No momento de transição democrática em nosso País, o programa pretendia atender a mulher de forma integral, respeitando suas necessidades e particularidades. Considerava-se não só que as mulheres "fossem tratadas como cidadãs, na plenitude de seus direitos, o que incluía a atenção à sua saúde como um todo, e não apenas como mães em potencial" (NAGAHAMA; SANTIAGO, 2005, p. 654), mas também que novas práticas em saúde por parte dos profissionais adviessem.

Contudo, o que se deu foi que, enquanto política ampla de saúde integral, este nunca foi adequadamente implementado, restando às mulheres uma série de transformações no cotidiano, que em muito se apresentavam como violências travestidas em cuidados.

O Programa de Atenção Integral à Saúde da Mulher (PAISM), por exemplo, reconhecia o tratamento impessoal e muitas vezes agressivo da atenção à saúde das mulheres. Porém, ainda que o tema estivesse na pauta feminista e mesmo na de políticas públicas, foi relativamente negligenciado, diante da resistência dos profissionais e de outras questões urgentes na agenda dos movimentos, e do problema da falta de acesso das mulheres pobres a serviços essenciais. (DINIZ et al., 2015, p. 378).

O Estado, apesar dos vários acordos internacionais firmados, nunca investiu em uma política que objetivasse fazer frente à lógica ao discurso hegemônico, biomédico, mesmo que, ao longo dos anos, possam ter surgido uma série ações e discussões sobre o modelo de parto, ainda muito alicerçado em ações intervencionistas e medicalizadoras.

O Programa de Humanização no Pré-natal e Nascimento - PHPN (2000), cujas principais características são a integralidade da assistência obstétrica e a afirmação dos direitos da mulher, incorporados como diretrizes institucionais, por exemplo, tem despertado polêmicas e mobilizado defensores e opositores nos diversos segmentos envolvidos, dentro e fora das instituições de assistência ao parto no Brasil. (NAGAHAMA; SANTIAGO, 2005).

Isto porque a Política de Humanização se funda em um conjunto de conhecimentos, atitudes e práticas que visam à promoção do parto e do nascimento saudáveis e a prevenção de morbimortalidade materna e perinatal (Brasil, 2001), ao mesmo tempo em que pode representar um conjunto de regras coercitivas que, embora digam apontar para a diversidade e para o reconhecimento da individualidade, implicam em normatizações, controle dos corpos e métodos disciplinares. 
"Violência? Do que?": reflexões sobre a violência obstétrica a partir de uma ação extencionista

Das regras que fundamentam as relações institucionais, os conceitos básicos para compreensão da organização das instituições como núcleos de poder são três: a hierarquia - marca da subordinação -, a ordem - que garante a estrutura -, e a disciplina - que assegura as relações sociais (Luz, 1981 apud NAGAHAMA; SANTIAGO, 2005, p. 656).

O que de fato vemos é que, “o preço da melhoria das condições do parto foi a sua desumanização e a transformação do papel da mulher de sujeito para objeto no processo do parto e nascimento" (NAGAHAMA; SANTIAGO, 2005, p. 656).

\section{Para finalizar}

A assistência à saúde das mulheres é um campo que ilustra exemplarmente o quanto programas, documentos e declarações não são suficientes para mudar substancialmente os modelos assistenciais, as práticas em saúde e, em última instância, o próprio cenário de saúde da população. (BARBOSA, 2006, p. 327).

A violência obstétrica, em nosso percurso, não pode ser determinada como uma relação particular entre um determinado profissional e uma determinada mulher. Todavia, uma relação de poder entre um representante da instituição obstetrícia, detentora de um saber-poder sobre a gestação e o parto, e outro despido, a luz do saber hegemônico, de qualquer saber, inclusive sobre si e seu corpo: a mulher.

A violência pode ser favorecida pelo não reconhecimento, nas instituições de saúde - território onde o saber médico é hegemônico -, dos valores e conhecimentos das pacientes acerca de si, de seu corpo e de sua história. A falta de saber técnico, por parte das próprias mulheres e a falta de respeito para com aquilo que é compreendido como direitos sexuais e reprodutivos, além da imposição de normas e valores morais pelos profissionais prestadores da assistência, são fatores determinantes para a emergência da violência obstétrica.

O modelo de assistência ao parto no Brasil, apesar de vir tentando se transformar, ainda é produtor de muita violência e sofrimento. Ainda está centrado no modelo tecnicista, hegemônico, apesar das políticas de assistência e cuidados e de alguns discursos proferidos em nome da humanização.

A naturalização deste modelo de assistência se entranhou de tal modo na sociedade que fora legitimado, inclusive, pelas próprias mulheres, que, em nome de 'suposta segurança', relegaram suas histórias e seus corpos nas mãos daqueles que, historicamente, se tornaram detentores do saber sobre o corpo feminino. Como apontam Dias e Deslandes (2006), “todos os procedimentos praticados na assistência 
reforçam as ideias de que a mulher não é capaz de parir sem a tecnologia médica e de que sem corpo, sem esse controle, pode trazer riscos para o bebê" (p. 355).

O que surge desta (triste) história é o que hoje temos: Um longo caminho de luta a trilhar. Uma batalha que possa visibilizar não só o que as mulheres vivenciam, mas que também possa auxiliá-las na compreensão do que é violência obstétrica. Afinal, este não é um 'simples' erro médico, como algumas proferem. A violência obstétrica é uma violência, que se expressa no maltratar a mulher e traz consigo a marca das desigualdades de gênero.

A aposta na Roda de Conversa, enquanto metodologia de intervenção deu-se por entendermos ser ela uma grande aliada das ações extensionistas. Pela especificidade de ser aberta e não hierarquizadas, propiciam que saberes possam circular horizontalmente, promovendo, de fato, uma relação dialógica entre sociedade e universidade. Foi isso que tentamos possibilitar quando não impusemos formas nem reproduzimos discursos idealizados sobre a mulher e a maternidade, que silenciam nossas mulheres. Tínhamos o dever ético de escutá-las, a partir da singularidade de suas falas.

A conversa permitiu que o tema fosse tratado de forma real, a partir das experiências vividas por cada uma daquelas mulheres. Possibilitou que fossem escutadas acerca das violências sofridas no momento de seus partos e, como isso, possibilitou que elas percebessem que não estão sós e que o vivido comporta algo de inadmissível, de violação.

De fato, evidenciamos, com as essas mulheres, que a violência obstétrica atravessa a vida das mulheres brasileiras e, ainda, é legitimada como "natural", "normal" e até "necessária", apesar das Políticas Públicas apontarem para a humanização do parto e do nascimento. Consequentemente, temos que corroborar Barbosa (2006), que aponta que há ainda uma "enorme distância entre programas e a realidade sanitária e assistencial". (p. 327).

\section{Referências}

ANDRADE, B. P.; AGGIO, C. M.. Violência obstétrica: a dor que cala. In: Anais do III Simpósio Gênero e Políticas Públicas. GT3 - Violência contra a Mulher e Políticas Públicas. Londrina, ISSN 2177-8248. 2014. Disponível em: 
http://www.uel.br/eventos/gpp/pages/arquivos/GT3_Briena\%20Padilha\%20Andrade. pdf. Acesso em: 20 nov. 2016.

AGUIAR, J. M.. Violência institucional em maternidades públicas: hostilidade ao invés de acolhimento como uma questão de gênero. 2010. 215. Doutorado. Faculdade de Medicina da Universidade de São Paulo. Departamento de Medicina Preventiva. São Paulo, 2010.

ALGRANTI, L. M.. Prefácio. In: MARTINS, A. P.. Visões do Feminino: a medicina da mulher nos séculos XIX e XX. Rio de Janeiro: Editora Fiocruz, 2004.

ALTHUSSER, L.. Ideologia e aparelhos ideológicos do Estado. Lisboa: Editorial Presença, 1970.

BARBOSA, R.H. S.. Humanização da assistência à saúde da mulher: uma abordagem cítrica de gênero. In: DESLANDES, S. F. (org). Humanização dos cuidados em saúde. Conceitos, dilemas e práticas. Rio de Janeiro: Editora Fiocruz, 2006.

BARBOZA, L.P.; MOTA, A.. Violência Obstétrica: vivências de sofrimento entre gestantes do Brasil. Revista Psicologia, Diversidade e Saúde. v.5, n.1, p. 119-129, 2016. Disponível em: https://www5.bahiana.edu.br/index.php/psicologia/article/download/847/598. Acesso em: 20 dez. 2016.

DESLANDES, S. F. (org). Humanização dos cuidados em saúde. Conceitos, dilemas e práticas. Rio de Janeiro: Editora FIOCRUZ, 2006.

BRASIL. Ministério da Saúde. Portaria 569, de 1ํo de junho de 2000. Brasília: DF, 2000. Disponível em: http://bvsms.saude.gov.br/bvs/saudelegis/gm/2000/prt0569_01_06_2000_rep.html. Acesso em: 10 dez. 2016.

BRASIL. Ministério da Saúde. Secretaria de Políticas Públicas para as mulheres. Parto, aborto e puerpério: assistência humanizada à mulher. Brasília: Ministério da Saúde, 2001.

BRASIL. Ministério da Saúde. Secretaria de Atenção à Saúde. Pré-natal e Puerpério: atenção qualificada e humanizada - manual técnico. Brasília: Ministério da Saúde, 2005. Disponível em: http://bvsms.saude.gov.br/bvs/publicacoes/manual_pre_natal_puerperio_3ed.pdf. Acesso em: 10 dez. 2016.

CHAUÍ, M.. Participando do debate sobre mulher e violência. In: CHAUÍ, M. et al. (org.). Perspectivas antropológicas da mulher. Rio de Janeiro: Zahar, 1985.

CURI, P. L.; BAPTISTA, J. G. B.. Quando a universidade verte para a cidade: emancipando e formando sujeitos através das ações no território. Ensino Saúde e Ambiente. v. 9, n. 3, p.

269-282,

2016.

Disponível

em: 
http://ensinosaudeambiente.uff.br/index.php/ensinosaudeambiente/article/view/567. Acesso em: 22 dez. 2016.

DIAS, M. A.B.; DESLANDES, S. F.. Humanização da assistência ao parto no serviço público: reflexão sobre os desafios profissionais nos caminhos de sua implementação. In: DESLANDES, S. F. (org). Humanização dos cuidados em saúde. Conceitos, dilemas e práticas. Rio de Janeiro: Editora Fiocruz, 2006.

DINIZ, S. G.; SALGADO, H. O.; ANDREZZO, H. F. A.; CARVALHO, P. G. C.; CARVALHO, P. C. A.; AGUIAR, C. A.; NIY, D. Y.. Violência obstétrica como questão para a saúde pública no Brasil: origens, definições, tipologia, impactos sobre a saúde materna, e propostas para sua prevenção. Journal of Human Growth and Development. v. 25, n.3, p. 377-384, 2015. Disponível em: http://pepsic.bvsalud.org/pdf/rbcdh/v25n3/pt_19.pdf. Acesso em: 20 dez. 2016.

FERREIRA, G. G; AGUINSKY, B. G. Movimentos sociais de sexualidade e gênero: análise do acesso às políticas públicas. R. Katál., Florianópolis, v. 16, n. 2, p. 223-232, 2013. Disponível em: http://www.scielo.br/pdf/rk/v16n2/08.pdf. Acesso em: 20 nov. 2016.

FOUCAULT, M. (1978-1979). Nascimento da biopolítica. 1 ed. São Paulo: Martins Fontes, 2008.

FOUCAULT, M. História da sexualidade I: a vontade de saber. Rio de Janeiro: Graal, 1988.

LAZZERI, T. Vítimas da violência obstétrica: o lado invisível do parto. Revista Época, 04 ago. 2015. Disponível em: http://epoca.globo.com/vida/noticia/2015/08/vitimas-daviolencia-obstetrica-o-lado-invisivel-do-parto.html. Acesso em: 22 dez. 2016.

LEAL, M. C.; PEREIRA, A. P. E.; DOMINGUES, R. M. S. M.; FILHA, M. M. T.; DIAS, M. A. B.; PEREIRA, M. N.; BASTOS, M. H.; GAMA, S. G. N. Intervenções obstétricas durante o trabalho de parto e parto em mulheres brasileiras de risco habitual. Caderno de Saúde Pública, Rio de Janeiro, v. 30, sup. S17-S47, 2014. Disponível em: http://www.scielo.br/pdf/csp/v30s1/0102-311X-csp-30-s1-0017.pdf. Acesso em: 20 dez. 2016.

MAIA, M.B. Humanização do parto. Política pública, comportamento organizacional e ethos profissional. Rio de Janeiro: Editora FIOCRUZ, 2010.

MAGAHAMA, E. E. I.; SANTIAGO, S. M. A institucionalização médica do parto no Brasil. Ciênc. saúde coletiva [online]. v.10, n.3, p. 651-657, 2005. Disponível em: http://dx.doi.org/10.1590/S1413-81232005000300021. Acesso em: 29 dez. 2016.

MARTINS, A. P. V.. Visões do feminino: a medicina da mulher nos séculos XIX e XX. Rio de Janeiro: Editora Fiocruz, 2004.

ORGANIZAÇÃO MUNDIAL DA SAÚDE. Care in normal birth: a practical guide. Genebra: OMS, 1996. 
"Violência? Do que?": reflexões sobre a violência obstétrica a partir de uma ação extencionista

http://apps.who.int/iris/bitstream/10665/63167/1/WHO_FRH_MSM_96.24.pdf. Acesso em: 05 dez. 2016.

ORGANIZAÇÃO MUNDIAL DA SAÚDE. Prevenção e eliminação de abusos, desrespeito e maus-tratos durante o parto em instituições de saúde. Genebra: OMS, 2014. Disponível em: http://apps.who.int/iris/bitstream/10665/134588/3/WHO_RHR_14.23_por.pdf. Acesso em: 31 dez. 2016.

ORGANIZAÇÃO DAS NAÇÕES UNIDAS. IV Conferência Mundial sobre a Mulher. Rio de Janeiro: Fiocruz, 1996.

ROHDEN, F.. Uma ciência da diferença: sexo e gênero na medicina da mulher. Rio de Janeiro: Editora Fiocruz, 2001.

ROHDEN, F.. (2006). Sexualidade e Gênero na Medicina. In: SOUZA, A. N.; PITANGUY, J. (orgs.). Saúde, corpo e sociedade. 2. ed. Rio de Janeiro: Editora UFRJ, 2014.

SENA, L. M.; TESSER, C. D.. Violência obstétrica no Brasil e o ciberativismo de mulheres mães: relato de duas experiências. Comunicação Saúde Educação, v. 21, n. 60, p. 209220, 2015. Disponível em: http://www.scielo.br/pdf/icse/v21n60/1807-5762-icse1807-576220150896.pdf. Acesso em: 20 dez. 2016.

VIEIRA, E. M.. A medicalização do corpo feminino. Rio de Janeiro: Editora Fiocruz, 2002.

WAGNER, M.. Fish can't see water: the need to humanize birth. Internacional Journal of Gynecology and Obstetrics. 2001. Disponível em: http://bhpelopartonormal.pbh.gov.br/estudos_cientificos/arquivos/fish_cant_see_wate r_the_need_to_humanize_birth.pdf. Acesso em: 20 nov. 2016. 
“Violência? Do que?": reflexões sobre a violência obstétrica a partir de uma ação extencionista

“Violence? of what?". Reflexions on obstetric violence from an extension action.

\section{ABSTRACT}

This study aims to discuss obstetric violence, based on an extension action carried out at a Basic Health Unit, in the city of Niterói, RJ, in commemoration of International Women's Day. With users of the health system, at different ages, the proposed Circles of conversations would have the intention of guiding them about the care and protection network for cases of exposure to sexual and / or domestic violence. However, what was presented was the so-called obstetric violence. Although they could not name the violence they had experienced, it was clear to the women that, in the name of childbirth care, they were unassisted and exposed to much suffering and pain.

\section{Keywords:}

Extension actions; Obstetric violence; Childbirth care.
"La violencia? ¿De qué?". Reflexiones sobre la violencia obstétrica a partir de una acción de extensión.

\section{RESUMEN}

Este trabajo tiene como objetivo la discusión de la violencia obstétrica a partir de una acción de extensión realizada en una Unidad Básica de Salud, en Niterói, RJ, en conmemoración por el Día Internacional de la Mujer. Con usuarias del sistema de salud de diversas edades, la Rueda de Conversación propuesta tuvo la intención de orientarlas sobre la red de asistencia y protección para los casos de exposición a la violencia sexual y/o doméstica. Sin embargo, lo que se manifestó fue la tan naturalizada violencia obstétrica. Aunque no se consiguió nombrar las violencias vividas, las mujeres dejaron claro que, bajo el nombre de la asistencia (apoyo) al parto, estas mujeres fueron en realidad expuestas a mucho sufrimiento y dolor.

Palabras clave:

Acción de extensión; Violencia obstétrica; Apoyo al parto.

Original submetido em: 10 jan. 2017

Aceito para publicação em: 6 dez. 2017

Sobre as autoras:

Paula Land Curi

Professora Adjunta do Instituto de Psicologia e Coordenadora da Curso de Psicologia, Universidade Federal Fluminense.

\section{Natália Lucena Guimarâes}

Discente do Curso de Psicologia, Universidade Federal Fluminense. 